\title{
Micro-porous membrane liquid-liquid extraction as an enrichment step prior to nonaqueous capillary electrophoresis determination of sulfonylurea herbicides
}

\author{
Qingxiang Zhou ${ }^{\mathrm{a}, \mathrm{b}}$, Jingfu Liu ${ }^{\mathrm{a}}$, Yaqi Cai ${ }^{\mathrm{a}}$, Guoguang Liu ${ }^{\mathrm{b}}$, Guibin Jiang ${ }^{\mathrm{a} *}$ \\ ${ }^{a}$ Research Center for Eco-Environmental Sciences, Chinese Academy of Sciences, P.O. Box 2871, Beijing 100085, PR China \\ ${ }^{\mathrm{b}}$ Key Laboratory of Environmental Sciences and Engineering of High Education of Henan Province, \\ School of Environmental Sciences and Chemistry, Henan Normal University, Xinxiang 453002, Henan, PR China
}

Received 14 October 2002; received in revised form 9 December 2002; accepted 19 December 2002

\begin{abstract}
A method based on micro-porous membrane liquid-liquid extraction (MMLLE) enrichment and nonaqueous capillary electrophoresis (CE) separation, was established for the analysis of sulfonylurea herbicides in water samples. After MMLLE, the analyte trapped in the chloroform was treated mildly with nitrogen flow to dryness and then dissolved in $200 \mu \mathrm{l}$ of $4 \mathrm{mM}$ Tris methanol solution for CE analysis. Five sulfonylurea herbicides were separated by nonaqueous $\mathrm{CE}$ with Tris/acetate of methanol solution as the run buffer. MMLLE related parameters such as organic solvent used as acceptor, sample flow rate, sample $\mathrm{pH}$, enrichment time, and salt effect were investigated with tribenuron methyl (TBM) as a model compound. Results showed that with a sample flow rate of $3.0 \mathrm{ml} \mathrm{min}^{-1}$ and an enrichment time of $20 \mathrm{~min}$, the proposed method has good linear relationship over the scope of $1-15 \mathrm{ng} \mathrm{ml}^{-1}$ with related coefficient of $R^{2}=0.9911$, and a detection limit of $0.4 \mathrm{ng} \mathrm{ml}^{-1}$. This method was applied to determine TBM in realworld water samples with recoveries over the range of $89-97 \%$.
\end{abstract}

(C) 2002 Elsevier Science B.V. All rights reserved.

Keywords: Micro-porous membrane liquid-liquid extraction; Nonaqueous capillary electrophoresis; Sulfonylurea herbicides

\section{Introduction}

The sulfonylurea herbicides are widely used for the control of weeds in agriculture crops, since they have been developed in 1970s [1,2]. Due to their higher herbicidal activity, the sulfonylurea herbicides are used with application dosages 1001000 times lower than that of conventional herbi-

\footnotetext{
*Corresponding author. Fax: + 86-10-62849179.

E-mail address: gbjiang@mail.rcees.ac.cn (G. Jiang).
}

cides. Their low application rates and low toxicity to humans and animals lead to the increase of consumption. Although sulfonylurea herbicides provide many environmental benefits, some of them are potential to persist in environment with quantities enough to damage the susceptible crops [3-5]. Owing to the complex environmental matrices, the expected low residue makes their determination difficult. Therefore, effective pretreatment steps and sensitive analysis method are highly important. 
Available methods for the determination of sulfonylurea herbicides are various according to the instrument and the pretreatment in the references. High performance liquid chromatography (HPLC) is the most often used technique [6-8]. The sensitivity of UV detector of HPLC is very poor, so photoconductivity [9-12] and mass spectrometry detectors [13-16] are alternative to improve the sensitive of the method.

Compared to liquid chromatography, capillary electrophoresis (CE) can provide better resolution and similar sensitivity [17] and was adopted as an alternative for analysis of sulfonylurea herbicides in environmental samples. Dinelli [18] developed a CE method for the determination of metsulfuron and chlorsulfuron in tap water. Later, he proposed another multi-residue analytical method based on solid phase extraction (SPE) enrichment combined with $\mathrm{CE}$ for determining ppb level of three sulfonylurea herbicides (chlorsulfuron, chlorimuron, and metsulfuron) in soil samples [19], and investigating sulfonylurea metabolites in water [20]. Krynitsky [21] analyzed sulfonylurea herbicides at ultratrace levels in marsh water samples. Residues of primisulfuron and triasulfuron in water and soil samples were also determined by a micellar electrokinetic capillary chromatography method [22]. Although CE applications in nonaqueous media have been paid more attention because of its special characteristics in the recent years [23-26], no application in analysis of sulfonylurea herbicides has been reported.

Because of the poor sensitivity of CE with UV detector, sample enrichment is indispensable to determine trace level analytes in environmental samples. Liquid-liquid extraction (LLE) and SPE are extensively used techniques for this purpose. Currently membrane-based extraction techniques were used as alternatives to LLE [27].

The objective of this study was to investigate the possibility of micro-porous membrane liquidliquid extraction technique (MMLLE) as a preconcentration step for $\mathrm{CE}$ in nonaqueous media, and exploit nonaqueous $\mathrm{CE}$ to separate sulfonylurea herbicides. Nonaqueous CE separation conditions were simply optimized. MMLLE parameters that impacts on the enriching efficiency were investi- gated by using tribenuron methyl (TBM) as the model compound.

\section{Materials and methods}

\subsection{Reagents}

Five sulfonylurea herbicide standards, metsulfuron methyl (MSM, 98.5\%, CAS number 7422364-6), bensulfuron methyl (BSM, 97.7\%, CAS number 83055-99-6), TBM (90.5\%, CAS number 101200-48-0), sulfometuron methyl (SMM, $74.5 \%$, CAS number 74222-97-2), ethametsulfuron (EMS, 90\%, CAS number 97780-06-8) were obtained from Tianjin Pesticides Factory (Tianjin, China) (Fig. 1). Stock solutions of these compounds were prepared without further purification and refrigerated at $4{ }^{\circ} \mathrm{C}$. Methanol (gradient HPLC grade, J\&KCHEMICA), Tris(hydroxymetyl)aminomethane (Tris, 99.9\%, Biochemical regent, Angus), acetic acid, sulfuric acid, dichoromethane, chloroform, sodium hydroxide were all analytical grade unless otherwise stated. Tris and acetic acid were prepared at a concentration of $100 \mathrm{mM}$ with methanol, respectively, and filtered through 0.45 $\mu \mathrm{m}$ membrane for further use. Millipore ultrapure water was used for washing process of CE.

\subsection{Apparatus}

CE was performed using an $\mathrm{HP}^{3 \mathrm{D}}$ system (Agilent Technologies, USA) equipped with an on column diode array detector. Detection wavelength of $239 \mathrm{~nm}$ was used throughout. Uncoated narrow bore silica capillaries (purchased from Hebei Yongnian Ruifeng Chromatographic Implements Ltd., Hebei, China) with an inner diameter of 75 $\mu \mathrm{m}$, a total length of $40 \mathrm{~cm}$ and effective separation length of $31.5 \mathrm{~cm}$ were used, all over the experiment the temperature was thermostated to $25{ }^{\circ} \mathrm{C}$, a constant voltage of $-25 \mathrm{kV}$ was kept for the electrophoretic separation. New capillary was rinsed with $1 \mathrm{M}$ sodium hydroxide for $10 \mathrm{~min}$. Before injections, the capillary was conditioned by flushing with $1 \mathrm{M}$ sodium hydroxide for $10 \mathrm{~min}$, water for $5 \mathrm{~min}$, methanol for $10 \mathrm{~min}$, and run buffer for $20 \mathrm{~min}$. After each run the capillary was washed for $3 \mathrm{~min}$ with the separation electrolyte. 


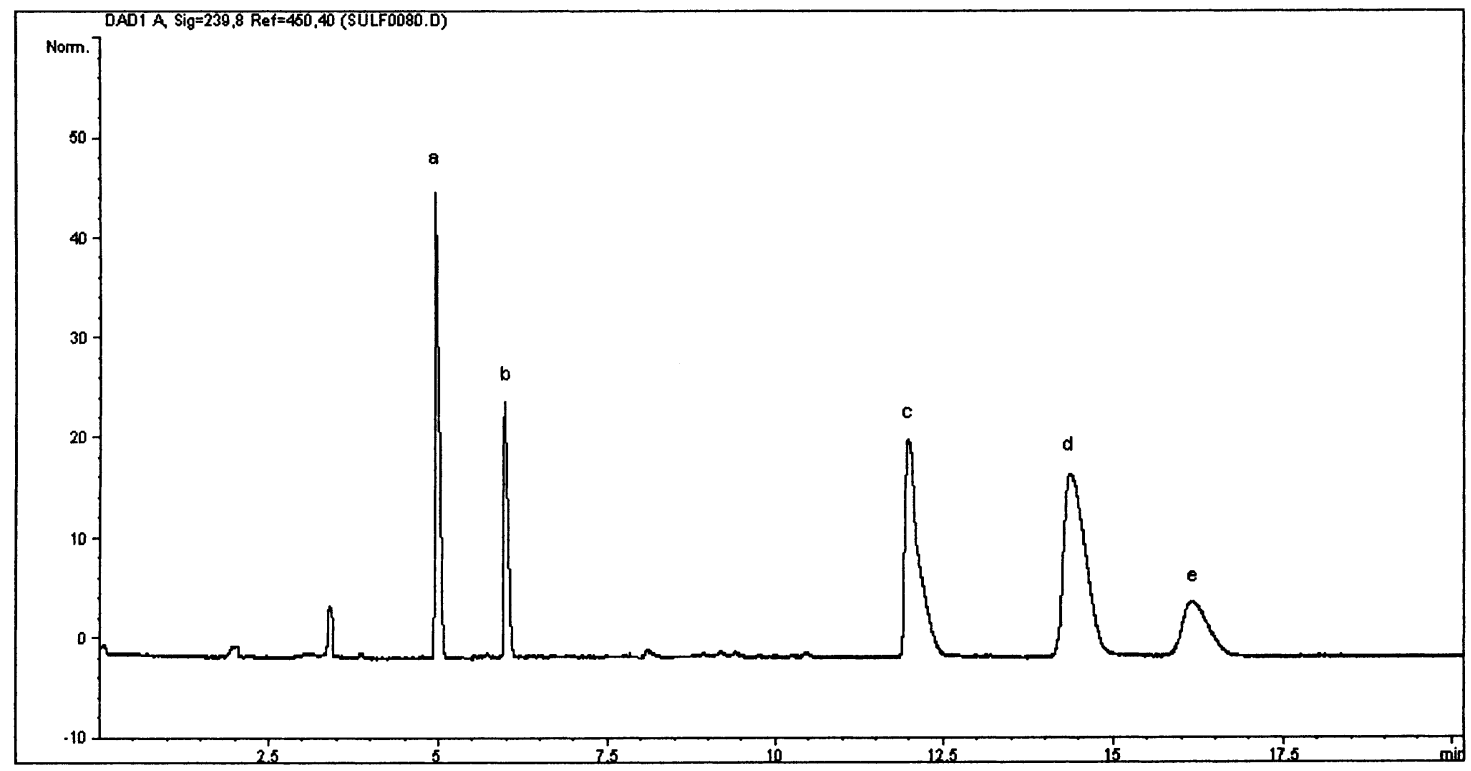

Fig. 1. Electrophoregram of five sulfonylurea herbicides, (a) TBM; (b) MSM; (c) SMM; (d) EMS; (e) BSM. Conditions: Injection voltage, $-14 \mathrm{kV}$; injection time, $25 \mathrm{~s}$; separation voltage, $-25 \mathrm{kV}$; run buffer, Tris/acetate with 80:20 (v:v).

Separation buffer was prepared by freshly mixing $100 \mathrm{mM}$ Tris and acetic acid of methanol solutions according to the needed percent.

The self-made MMLLE equipment consisted of PTFE holder, PTFE membrane, aluminum backer and two six-port valves. The PTFE holder was machined from two blocks of Teflon by cutting two Archimedes' spiral grooves on the opposite faces of the two blocks. The grooves have identical dimensions of $0.3-\mathrm{mm}$ deep, 2.0-mm wide and $160-\mathrm{cm}$ long. The PTFE membrane (Fluoropore FG PTFE membrane with average pore size 0.2 $\mu \mathrm{m}$, porosity 0.7 ; Millipore Co., Bedford, MA) was clamped tightly and evenly between the planar surfaces of the blocks by eight screws. Thus, two channels (the acceptor channel and the donor channel) with the same volume of $960 \mu \mathrm{l}$ were obtained. The polyethylene backing of the PTFE membrane was teared to prevent it dissolving in organic solvent. To make the device more rigid, each PTFE block were backed by an aluminum block. One six-port valve was used to control the entrance of sample solution into the donor of extraction system, the other one was exploited to load and take out the organic solvent and keep the channel airproof during the extraction procedure.

\subsection{Sample preparation}

Water samples of $5 \mu \mathrm{g} \mathrm{ml}^{-1}$ TBM were obtained by fortifying with stock solution to freshly filtered de-ionized water for optimizing operations. Sample was loaded into the extraction system with a piston pump when the acceptor channel was full of organic solvent. After a scheduled interval, the organic phase was deposited into the graduated cuvette with a syringe, and blown to dryness with gentle nitrogen flow, thereafter, $200 \mu \mathrm{l}$ of $4 \mathrm{mM}$ of Tris methanol solution was added. These solutions were sonicated for $10 \mathrm{~min}$, and steady for analysis by $\mathrm{CE}$.

\subsection{Real sample analysis}

Realworld water samples, collected from local water reservoir, the effluent of a wastewater treatment factory, and tap water were analyzed. These samples were filtered through the $0.45 \mu \mathrm{m}$ micro- 
pore membrane, and then analyzed following the same process as for the standard solution as described above.

\section{Results and discussion}

\subsection{Separation of sulfonylurea herbicides}

CE separation of sulfonylurea herbicides was usually performed by converting sulfonylurea herbicides into the anion at $\mathrm{pH} 9.0$, or by partitioning these compounds into micelles at $\mathrm{pH}$ 7.0. In this present study, however, the separation buffer must be re-optimized as the separation was conducted in nonaqueous medium. The $\mathrm{pH}$ of $100 \mathrm{mM}$ Tris/ acetate buffer was adjusted to approximately 8.0 by changing the volume percent of Tris and acetic acid. A series of Tris/acetate buffer consists of different volume ratio of acetic acid and Tris were investigated for electrophoretic separation. Results showed that the buffers with ratios of 10:90, 20:80 and 30:70 all had excellent resolution ability (the data are not shown) but the highest peak height of each compound was obtained at the ratio of 20:80. Probably due to the $\mathrm{pH}$ being not high enough to make the sulfonylurea compounds ionize, no peaks were found in the ratio of 50:50, and only four peaks were exhibited on the electrophoregram at ratio of 40:60. Hence, the buffer solution with the ratio of 20:80 was adopted as the run buffer for the further research.

To date many trace-enrichment techniques in $\mathrm{CE}$ such as on-line isotachophoresis prior to capillary zone electrophoresis separation [27,28], field amplification [29,30], large-volume stacking and electrostacking [31] have been reported. Electrostacking has the advantage of processing isotachophoretic preconcentration and separation in the same capillary [32]. Considering MMLLE has limited enrichment factor, online stacking was taken into account in this study to obtain lower detection limit. Preliminary experiments were performed to investigate the influence of the injection voltage and time by changing voltage value of $-10,-12,-14,-16,-18 \mathrm{kV}$ with constant time of $25 \mathrm{~s}$, or altering injection time from 10 to $35 \mathrm{~s}$ at intervals of $5 \mathrm{~s}$ while keeping the injection

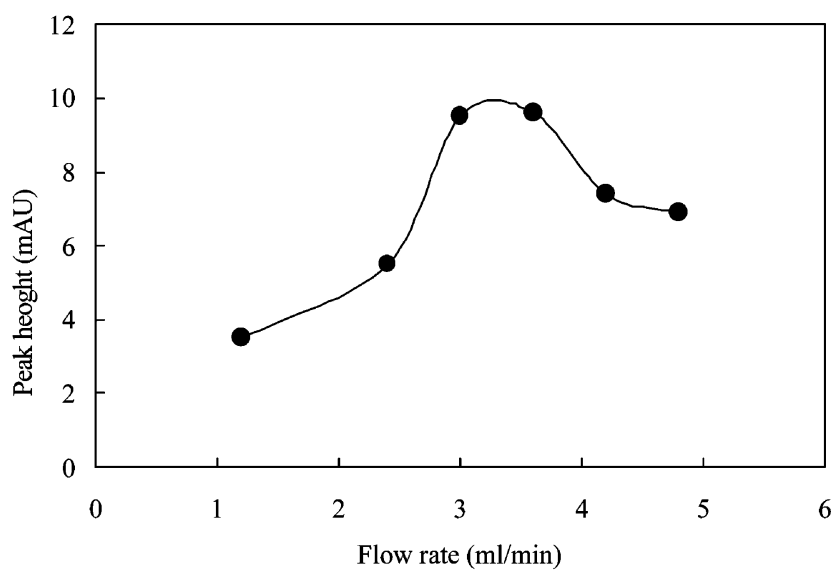

Fig. 2. Effect of flow rate.

voltage invariable. As a result, $-14 \mathrm{kV}$ and $25 \mathrm{~s}$ were selected for followed experiments.

\subsection{Optimization of MMLLE operation}

Extraction efficiency of MMLLE is related to many factors such as material and pore size of membrane and organic solvent used as acceptor. Fluoropore FG PTFE was used throughout in this present study. Several organic solvents were tried as acceptor in MMLLE. Experiments showed that while hexane almost cannot enrich the sulfonylurea compounds, dichloromethane and chloroform have a higher enrich factor. This consequence is in agreement with the principle of likes dissolve in likes because the sulfonylurea compounds are polar compounds. Considering that dichloromethane has relatively high volatility and low boiling point, which leads to its fast loss out in the enrichment procedure, chloroform was adopted as acceptor phase organic solvent.

\subsubsection{Effect of flow rate}

With the constant acidity value of $\mathrm{pH} 0.7$ and extraction time of $20 \mathrm{~min}$, the flow rate was optimized in the range of $1.2-4.8 \mathrm{ml} \mathrm{min}^{-1}$ and the result is shown in Fig. 2. The peak height of TBM increased from the beginning because the volume of sample solution through the extraction system was enlarged with the increasing of flow rate and the quantity of TBM through the 


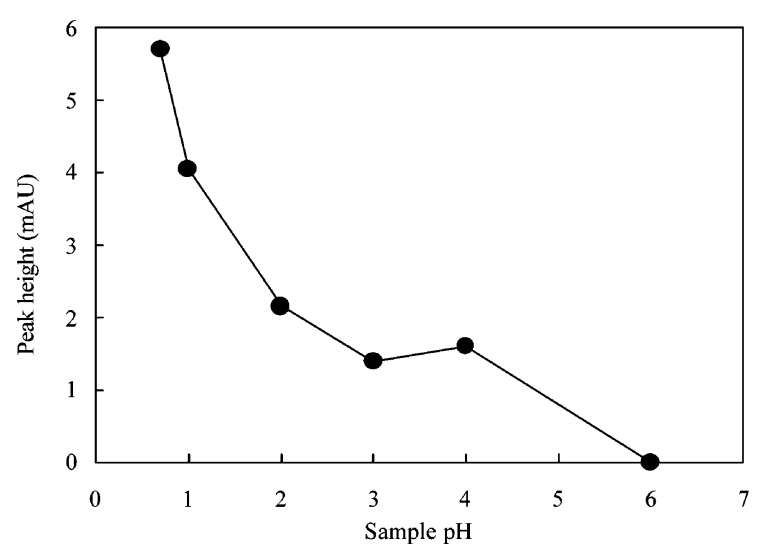

Fig. 3. Effect of sample pH.

membrane transferred into organic phase was increased accordingly. Within the rate of 3.0-3.6 $\mathrm{ml} \mathrm{min}-1$, the distributing equilibrium of analyte in between the two phases maybe reached and TBM could be trapped in the chloroform phase at the highest degree. Over the flow rate of 3.6 $\mathrm{ml} \mathrm{min}{ }^{-1}$, the peak height value diminished slowly perhaps due to similar vacuumizing effect of large flow rates that altered the balance of TBM between donor and acceptor phases. Therefore, 3.0 $\mathrm{ml} \mathrm{min}{ }^{-1}$ was adopted in the latter experiments.

\subsubsection{Effect of sample solution $\mathrm{pH}$}

TBM is a weak acid compound, which must be turn into a neutral molecule form for the sake of being better trapped into chloroform. No doubt acidity of sample was one of the main complications to the enrichment. The effect of sample $\mathrm{pH}$ was studied over the range of $0.7-6$, adjusted with $3 \mathrm{M}$ sulfuric acid, by enriching samples prepared by fortifying the working solution into freshly filtered ionized water with an extraction time of $20 \mathrm{~min}$ at ambient temperature. Results shown in Fig. 3 indicate that sample $\mathrm{pH}$ had significant effect on the trapping of TBM. No TBM was found in the chloroform acceptor at sample $\mathrm{pH}$ 6.0 , while the responses increased dramatically at $\mathrm{pH} \leqslant 1$. Considering TBM maybe degrade in strong acid environment, the samples were adjusted to $\mathrm{pH} 1.0$ in the following study.

\subsubsection{Effect of enrichment time}

Generally, enrichment factor increased with the prolonging of enrichment time. Results shown in Fig. 4 indicate that if the enrichment time over 20 min, the enrichment factor reached an approximately constant value and did not increase with the time enlarging. This result was basically consistent with that of determining phenols by MMLLE online coupled with multidimensional liquid chromatography [33].

\subsubsection{Effect of salting out}

Adding salt to the aqueous sample solution often provides much higher extraction recovery in traditional LLE of polar compounds. The effect of salt was studied by changing the contents of $\mathrm{NaCl}$ in the range of $5-25 \%$ and the results demonstrated that the response increased weakly with the enlarging of $\mathrm{NaCl}$ content. Hence, salting out had a little distribution to the trapping efficiency and no salt was used in the followed procedure.

\subsection{Calibration and detection limit}

Under the above optimized experimental conditions, five standard solutions over the range of 1-15 $\mathrm{ng} \mathrm{ml}^{-1}$ were analyzed for obtaining the linear scope, detection limit and other characters of the method. The reproducibility was evaluated by measuring $5 \mathrm{ng} \mathrm{ml}^{-1}$ of TBM with 5 runs. The peak height of TBM was found to be linear over the whole range tested, and the regression equation of standard curve was $H=1.4835 C+0.1581$ with

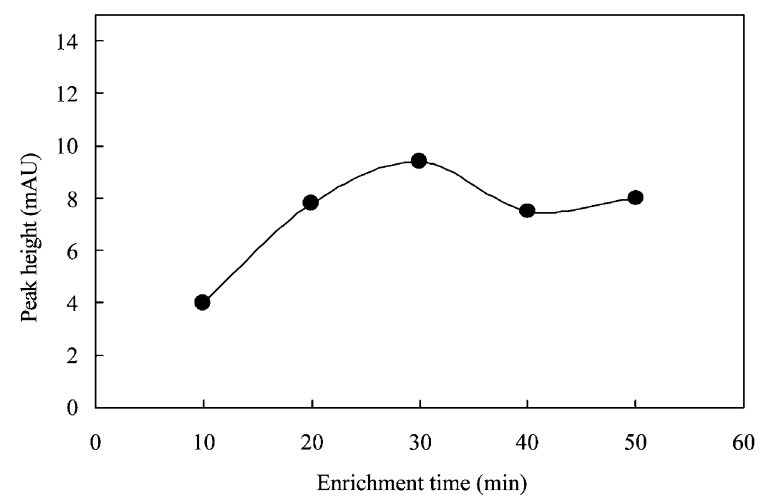

Fig. 4. Effect of enrichment time. 
Table 1

Mean recovery of real water spiked with $\mathrm{TBM}$ at $5 \mathrm{ng} \mathrm{ml}^{-1}$ level

\begin{tabular}{ll}
\hline Water matrix & Recovery $(\%)^{\mathrm{a}}$ \\
\hline Tap water & $97 \pm 5$ \\
Reservoir water & $94 \pm 5$ \\
Discharged water of waste water factory & $89 \pm 1$ \\
\hline
\end{tabular}

${ }^{\mathrm{a}}$ Mean and S.D. for three determinations.

a correlation coefficient of $R^{2}=0.9911$. The detection limit was $0.4 \mathrm{ng} \mathrm{ml}^{-1}(S / N=3)$, and the reproducibility (R.S.D.) was $11 \%(n=7)$.

\subsection{Analysis of realworld sample}

In order to validate the proposed method, three aqueous samples including tap water, reservoir water and municipal sewage effluent were analyzed and the recoveries were determined by spiking the samples with $5 \mathrm{ng} \mathrm{ml}^{-1} \mathrm{TBM}$. Experiments show that no TBM was detected, and the spiked recoveries were shown in Table 1 . The results confirmed the applicability of MMLLE prior to $\mathrm{CE}$ for checking the presence of TBM in water environment.

\section{Conclusions}

A novel and effective method for separation and determination of sulfonylurea herbicides by nonaqueous CE after MMLLE has been established. Nonaqueous capillary electrophoretic separation of sulfonylurea herbicides was first reported and baseline separation under very simple conditions was obtained. The MMLLE was carried out to enhance the concentration sensitivity of $\mathrm{CE}$ analysis in the optimum parameters, and reasonable detection limit of $0.4 \mathrm{ng} \mathrm{ml}^{-1}$ was obtained, which was markedly lower than that of $\mathrm{CE}$ alone. Compared with the existing method, this proposed procedure has the advantage of low consumption of organic solvent due to the adoption of MMLLE and nonaqueous $\mathrm{CE}$ techniques. This method can be used for determination of sulfonylurea herbicides at low ppb level.

\section{Acknowledgments}

The $\mathrm{HP}^{3 \mathrm{D}} \mathrm{CE}$ system used in this work was friendly provided by Agilent Technologies. This work was financially supported by the National Natural Science Foundation of China (20137010, 20177026) and the Chinese Academy of Sciences (KZCX2-414).

\section{References}

[1] H.M. Brown, Pestic. Sci. 29 (1990) 263.

[2] J. Tekel, J. Kovacicova, J. Chromatogr. 643 (1993) 298.

[3] A. Vicari, P. Catizone, R.L. Zimdahl, Weed Res. 34 (1994) 147.

[4] M.A. Peterson, W.E. Arnold, Weed Sci. 34 (1985) 131.

[5] E.M. Beyer, M.J. Duffy, J.V. Hay, D.D. Schlueter, in: P.C. Kearney, D.D. Kaufmann (Eds.), Herbicides: Chemistry, Degradation and Mode of Action, vol. 3, Marcel Dekker, New York, 1988, p. 117, Ch. 3.

[6] P. Klaffenbach, P.T. Hollander, Biol. Mass Spec. 22 (1993) 565

[7] A.J. Krynitsky, D.M. Swineford, J. AOAC Int. 78 (1995) 1091.

[8] G. Dinelli, A. Vicari, P. Catizone, J. Agric. Food Chem. 41 (1993) 742.

[9] E.W. Zahnow, J. Agric. Food Chem. 30 (1982) 854.

[10] E.W. Zahnow, J. Agric. Food Chem. 33 (1985) 479.

[11] E.W. Zahnow, J. Agric. Food Chem. 33 (1985) 1206.

[12] R.V. Slates, J. Agric. Food Chem. 36 (1988) 1207.

[13] A.C. Barefoot, R.W. Reiser, S.A. Cousins, J. Chromatogr. 474 (1989) 39.

[14] A.C. Barefoot, R.W. Reiser, J. Chromatogr. 398 (1987) 217.

[15] A.C. Barefoot, R.W. Reiser, Biomed. Environ. Mass Spectrom. 18 (1989) 77.

[16] R.W. Reiser, A.C. Barefoot, R.F. Dietrich, A.J. Fogiel, W.R. Johnson, M.T. Scott, J. Chromatogr. 554 (1991) 91.

[17] N.A. Guzman, Capillary Electrophoresis Technology, Marcel Dekker, Inc, New York, NY, 1993, pp. iii-iv.

[18] G. Dinelli, A. Vicari, P. Catizone, J. Agric. Food Chem. 41 (1993) 742.

[19] G. Dinelli, A. Vicari, V. Brandolini, J. Chromatogr. A 700 (1995) 201.

[20] G. Dinelli, A. Vicari, A. Bonetti, J. Chromatogr. A 700 (1995) 195

[21] A.J. Krynitsky, J. AOAC Int. 80 (1997) 392.

[22] K.V. Penmetsa, R.B. Leidy, D. Shea, J. Chromatogr. A 766 (1997) 225.

[23] M. Jansson, J. Roeraade, J. Chromatogr. 40 (1995) 163.

[24] A. Karbaum, T. Jira, Electrophoresis 20 (1999) 3396.

[25] I. Bjørnsdottir, J. Tjørnelund, S.H. Hansen, Electrophoresis 19 (1998) 2179. 
[26] W. Lu, G. Yang, R.B. Cole, Electrophoresis 16 (1995) 487.

[27] V. Dolnik, M. Deml, P. Bocek, J. Chromatogr. 320 (1985) 89.

[28] D. Kaniansky, J. Marak, J. Chromatogr. 498 (1990) 191.

[29] R.-L. Chien, D.S. Burgi, Anal. Chem. 64 (1992) 489A.
[30] R.-L. Chien, D.S. Burgi, Anal. Chem. 64 (1992) 1046.

[31] P. Jandik, W.R. Jones, A. Weston, P.R. Brown, LC.GC 9 (1991) 634.

[32] P. Jandik, W.R. Jones, J. Chromatogr. 546 (1991) 431.

[33] T. Hyötyläinen, T. Andersson, M. Jussila, et al., J. Sep. Sci. 24 (2001) 544. 